\title{
Management, outcome, and novel classification system of periprosthetic fractures in patients with transcutaneous osseointegrated prosthetic systems (TOPS) - a retrospective cohort analysis
}

\author{
Marcus Örgel ${ }^{1}(1) \cdot$ Maximilian Petri $^{2} \cdot$ Alexander Ranker $^{3} \cdot$ Nils Wirries $^{2} \cdot$ Tilman Graulich $^{1} \cdot$ Christian Krettek $^{1}$. \\ Marcel Winkelmann ${ }^{1} \cdot$ Horst-Heinrich Aschoff ${ }^{1}$
}

Received: 7 December 2020 / Accepted: 8 February 2021 / Published online: 6 March 2021

(c) The Author(s) 2021

\begin{abstract}
Introduction Transcutaneous osseointegrated prosthetic systems (TOPS) are anchored prosthetic systems for major limb loss. Sometimes TOPS patients suffer from periprosthetic fractures. The aim of this study was to analyze the management and outcomes of periprosthetic fractures in patients with TOPS and to introduce a novel classification system for this entity. Material/methods Since 2010, 140 patients were treated with TOPS after transfemoral amputation in two centers in Germany. Fifteen patients sustained periprosthetic fractures, with five intra- and ten postoperative fractures. The outcome was analyzed by Prosthesis Mobility Questionnaire (PMQ), K-level and prosthesis wear time per day. A subgroup analysis for the body mass index (BMI) was performed.

Results All postoperative fractures were treated with implant-retaining osteosynthesis. Fourteen fractures healed without complications after a mean of 3 months. One postoperative fracture developed a clinically asymptomatic firm non-union. No Endo-Fixstem had to be removed. For the fracture and control group, a significant increase of the PMQ $(p<0.001)$ and K-level $(p<0.001)$ was observed after TOPS treatment compared to the preoperative baseline. Furthermore, the subgroup analysis showed a significant increase of the PMQ and K-level for both normal weight $(p=0.002)$ and overweight patients $(p<0.001)$. Of interest, overweight patients even showed a significantly higher increase in scores compared to normal weight patients, regardless of periprosthetic fracture.

Conclusion Periprosthetic fractures do not necessarily worsen outcomes of TOPS treatment. Proper classification and standardized appropriate treatment strategies according to fracture morphology are paramount for reliably good outcomes. We recommend to not remove or exchange the implant (Endo-Fixstem) even if it is assembly. Higher BMI did not have an impact onto rehabilitation success after TOPS to major limb loss of the lower extremity.
\end{abstract}

Keywords Periprosthetic fractures - Transcutaneous osseointegrated prosthetic system (TOPS) - Endo-exo-prosthesis · Bone anchored prosthetic systems · Amputation $\cdot$ Rehabilitation

Marcus Örgel

Oergel.Marcus@mh-hannover.de

1 Trauma Department, Hannover Medical School (MHH), Carl-Neuberg-Straße 1, 30625 Hannover, Germany

2 Orthopaedic Department, Diakovere Annastift, Anna-von-Borries-Straße 1-7, 30625 Hannover, Germany

3 Department of Physical Medicine and Rehabilitation, Hannover Medical School (MHH), Carl-Neuberg-Straße 1, 30625 Hannover, Germany

$\begin{array}{ll}\text { Abbreviations } \\ \text { ASA } & \text { American Society of Anesthesiologists } \\ \text { BMI } & \text { Body mass index } \\ \text { CCI } & \text { Charlson Comorbidity Index } \\ \text { EEP } & \text { Endo-exo-prosthesis } \\ \text { DCS } & \text { Dynamic condyle screw } \\ \text { DHS } & \text { Dynamic hip screw } \\ \text { HCiopF } & \begin{array}{l}\text { Hannover classification of intraoperative } \\ \text { periprosthetic fractures }\end{array} \\ \text { HCpopF } & \begin{array}{l}\text { Hannover classification of postoperative } \\ \text { periprosthetic fractures }\end{array} \\ \text { HCFA } & \text { US Health Care Financing Administration }\end{array}$




$\begin{array}{ll}\text { HRQoL } & \text { Health-related quality of life } \\ \text { LISS } & \text { Less invasive stabilization system } \\ \text { PMQ } & \text { Prosthesis Mobility Questionnaire } \\ \text { TOPS } & \begin{array}{l}\text { Transcutaneous osseointegrated prosthetic } \\ \text { systems }\end{array} \\ \text { e.g. } & \text { Exempli gratia }\end{array}$

\section{Introduction}

In Germany, TOPS have been used for more than 15 years [1-3]. This procedure is applicable for patients suffering from an unsatisfying rehabilitation with socket prostheses due to soft tissue problems, short residual limbs, or other inabilities to fit any kind of socket prosthesis after transfemoral amputation $[4,5]$. One of the TOPS models is the endo-exo-prosthesis (EEP).

Endo-exo-prosthesis procedure includes two surgical steps at intervals of 4-6 weeks. In the first step, the EndoFixstem (implant) is anchored to the bone (endo). Depending on bone quality and primary stability during the first surgery, a stoma is performed in the second step at least four to six weeks after the first surgery with assembling of the components passing through the skin, to which the prosthetist and orthotist connects-the exo-prosthetics [2, 6]. After the first surgery, the bone grows into the three-dimensional surface structure (tripods) of the Endo-Fixstem and creates a strong connection between the bone and prosthesis. This provides a stable walking ability for the patient $[2,7]$. Rehabilitation starts with walking on crutches, parallel bars, or other helping tools.

Mostly, this type of prostheses leads to satisfying rehabilitation results with increasing mobility and daily activities [8, 9]. Leijendekkers et al. showed a significant increase of strength, prosthetic use, walking distance, health-related quality of life (HRQoL), and satisfaction level in their prospective one-year follow-up study [9]. Also, Brånemark et al. showed significant improvements for the use of the prosthesis, better mobility, and HRQoL [8].

A substantial incidence of periprosthetic fractures by falls has to be expected [8-12]. So far, there is only one study available about the risk of periprosthetic fractures in patients with osseointegrated implants after transfemoral amputation [12]. In this cohort, 22 patients suffered from a periprosthetic fracture related to TOPS. Neither the K-level nor the prosthesis wear time was negatively affected after fixation of the fracture in any patient [12].

According to this work, we analyzed periprosthetic fractures according to the management and outcome and described a novel classification system as well as treatment algorithm for periprosthetic fractures after TOPS treatment following transfemoral amputation in our consecutive cohort.

\section{Objectives}

The aims of this retrospective study were:

- To investigate the impact of periprosthetic fractures in patients with TOPS by comparing the outcomes in mobility [Prothesis Mobility Questionnaire (PMQ), $\mathrm{K}$-level] and prosthesis wear time in hours in TOPS patients with a periprosthetic fracture to TOPS patients without a periprosthetic fracture,

- To derive a classification system and treatment algorithm of periprosthetic fractures related to TOPS.

Our hypothesis was that there is no difference in the outcome of mobility (PMQ, K-level) and prosthesis wear time per day (in hours) in the fracture group compared to the non-fracture group.

\section{Methods}

This retrospective observational study examines the outcomes of TOPS patients who suffered from an intra- or postoperative periprosthetic fracture. In addition to demographic data, we assessed the mobility by the "Prothesis Mobility Questionnaire" (PMQ) as well as the K-level and the prosthesis wear time per day. These results were compared with TOPS patients who did not sustain a periprosthetic fracture. In addition, the cohort was divided into two subgroups according to their BMI (BMI $<25 \mathrm{~kg} / \mathrm{m}^{2}$ "normal weight patients" versus BMI $\geq 25 \mathrm{~kg} / \mathrm{m}^{2}$ "overweight patients") for analysis of the above-mentioned parameters.

Data collection was performed from an existing database of the Trauma Department of a University Hospital as well as through a structured telephone interview. Regardless to complications such as a periprosthetic fractures, all TOPS patients were evaluated in our clinic within the scope of a standardized assessment before, 3, 6, and 12 months after implantation of the Endo-Fixstem.

Between 2010 and 2017, 64 consecutive patients were included from center 1, while between 2017 and 2019, 76 consecutive patients were included from center 2 (Fig. 1). The reason for recruitment from two centers was professional relocation of the senior surgeon in 2017.

We included several demographic and clinical variables. Patient demographics included age and gender as well as age at amputation, time between amputation to TOPS, and sustaining the fracture. Clinical variables included BMI, PMQ, and K-level as well as time of using the prosthesis per day. Comorbidity was measured with Charlson Comorbidity Index (CCI) [13-15] and peri-/postoperative risk 
Fig. 1 Methods to examine subgroups and interactions; *Hannover Classification of postoperative periprosthetic Fractures (HCpopF); **Hannover Classification of intraoperative periprosthetic Fractures (HCiopF);

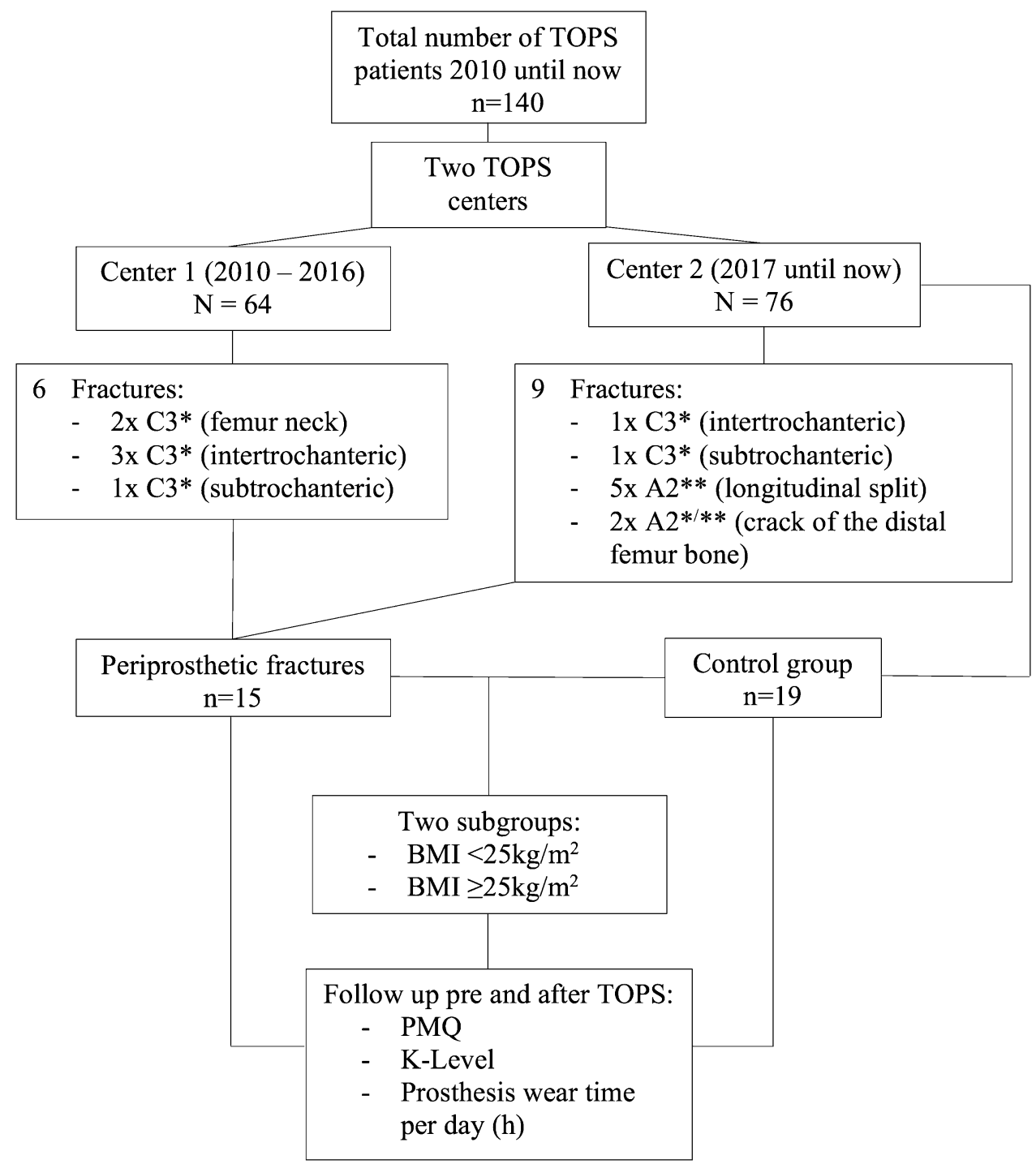

assed with American Society of Anesthesiologists (ASA) [16]. Detailed results are shown in Tables 1 and 2.

The original PMQ is a questionnaire with 12 questions about mobility in everyday life, which are answered on a 5-step Likert scale [17]. The PMQ 2.0 used in this study was derived from first version. The PMQ 2.0 is based on a Rasch analysis by Burger et al., which showed that in case of conflicting questions (e.g., I find it difficult to go upstairs or downstairs), it seems to make more sense to include only those questions in the overall score that are associated with greater difficulties [18]. The maximum total score is 40 , which presents the highest score for mobility.

In 1995, the US Health Care Financing Administration (HCFA) [19], a public administration and monitoring agency of the US Medicare and Medicaid program, introduced a classification system (K-level) for leg amputees. It consists of five function levels; K0 ("nonambulator") to K4 ("highlever user"), which are based on the abilities and potential of an amputee [20]. The classification refers to the walking potential of a patient and is based on subjective patient surveys [21]. Furthermore, the prosthesis wear time was documented in hours per day, which could indirectly provide an indication of mobility and prosthesis satisfaction.

In order to achieve the highest possible degree of objective comparability of the control group, we based the formation of the comparison cohort on parameters of the fracture group, such as gender, age, BMI, and the time of amputation and TOPS care and randomly selected patients from our database who had comparable basic data.

The study size was based on the number of all patients treated with TOPS in Germany since 2010 who suffered a fracture $(n=15)$ and were presented to our clinic. The comparison group $(n=19)$ was randomly selected from the existing database of TOPS patients.

Statistical analysis was performed using SPSS 26 (IBM, SPSS Inc., Chicago, IL). After checking for normal distribution 
Table 1 Demographic data of the whole cohort within subgroups (fracture and control group)

\begin{tabular}{|c|c|c|c|c|}
\hline & Total $(n=34)$ & Fracture group $(n=15)$ & Control group $(n=19)$ & $p$ value \\
\hline Sex, $n(\%)$ & & & & $0.2^{\mathrm{a}}$ \\
\hline Male & $25(73.5)$ & $13(86.7)$ & $12(63.2)$ & \\
\hline Female & $9(26.5)$ & $2(13.3)$ & $7(36.8)$ & \\
\hline Side, $n(\%)$ & & & & $0.3^{\mathrm{d}}$ \\
\hline Left & $13(38.2)$ & $8(53.3)$ & $11(57.9)$ & \\
\hline Right & $19(55.9)$ & $5(33.3)$ & $0(0)$ & \\
\hline Bilateral & $2(5.9)$ & $2(13.3)$ & $8(42.1)$ & \\
\hline Reason for amputation, $n(\%)$ & & & & $0.5^{\mathrm{d}}$ \\
\hline Trauma & $23(67.6)$ & $12(80.0)$ & $11(57.9)$ & \\
\hline Tumor & $1(2.9)$ & 0 & $1(5.3)$ & \\
\hline Vascular disease & $1(2.9)$ & 0 & $1(5.3)$ & \\
\hline Iatrogenic complications & $9(26.5)$ & $3(20.0)$ & $6(31.6)$ & \\
\hline Age [years], mean \pm SD $(95 \%$-CI $)$ & $48.7 \pm 9.6(45.4-52.1)$ & $49.1 \pm 11.6(42.7-55.6)$ & $48.4 \pm 8.1(44.5-52.3)$ & $0.8^{\mathrm{e}}$ \\
\hline Age at amputation [years] mean $\pm \mathrm{SD}(95 \%$-CI $)$ & $32.9 \pm 13.0(28.5-37.5)$ & $29.9 \pm 13.3(22.5-37.2)$ & $35.4 \pm 12.5(29.4-41.5)$ & $0.2^{\mathrm{b}}$ \\
\hline $\mathrm{BMI}\left[\mathrm{kg} / \mathrm{m}^{2}\right]$ mean $\pm \mathrm{SD}(95 \%-\mathrm{CI})$ & $26.6 \pm 4.3(25.1-28.1)$ & $25.7 \pm 4.5(23.2-28.2)$ & $27.3 \pm 4.2(25.3-29.4)$ & $0.3^{\mathrm{e}}$ \\
\hline $\begin{array}{l}\text { Months amputation to TOPS mean } \pm \text { SD }(95 \% \text { - } \\
\text { CI) }\end{array}$ & $149.7 \pm 132.6(103.4-196.1)$ & $167.5 \pm 150.2(84.3-250.7)$ & $135.7 \pm 119.3(78.2-193.2)$ & $0.6^{\mathrm{b}}$ \\
\hline $\begin{array}{l}\text { Prosthesis wear time per day [hours] } \\
\text { mean } \pm \text { SD }(95 \%-C I)\end{array}$ & $12.8 \pm 4.0(11.4-14.2)$ & $12.1 \pm 4.2(9.8-14.5)$ & $13.3 \pm 3.9(11.4-15.1)$ & $0.2^{\mathrm{b}}$ \\
\hline ASA Score mean \pm SD $(95 \%-C I)$ & $2.0 \pm 0.3(1.9-2.1)$ & $1.9 \pm 0.5(1.7-2.2)$ & $2.1 \pm 0.2(1.9-2.2)$ & $0.3^{\mathrm{d}}$ \\
\hline $\mathrm{CCI}[\%]$ mean $\pm \mathrm{SD}(95 \%-\mathrm{CI})$ & $94.3 \pm 8.8(91.2-97.4)$ & $92.5 \pm 12.2(85.8-99.3)$ & $95.7 \pm 4.6(93.5-98.0)$ & $0.7^{\mathrm{b}}$ \\
\hline
\end{tabular}

Table 2 Data of special findings to the fracture group

\begin{tabular}{ll}
\hline & \\
\hline Cause of fracture, $n(\%)$ & Fracture group $(n=15)$ \\
Slipped & $2(13.3)$ \\
Stumbling & $5(33.3)$ \\
Malfunction of the prosthesis & $1(6.7)$ \\
Intraoperative fracture & $7(46.7)$ \\
Morphology of the fractures, $n(\%)$ & \\
C3*** (femur neck) & $2(13.3)$ \\
C3*** (intertrochanteric) & $4(26.7)$ \\
C3*** (subtrochanteric) & $2(13.3)$ \\
A2*** (longitudinal split of the femur) & $5(33.3)$ \\
A2*** (distal femur) & $2(13.3)$ \\
Treatment, $n(\%)$ & $1(6.7)$ \\
DCS* plate 95 + cerclage wire & $2(13.3)$ \\
LISS** plate + cerclage wire & $1(6.7)$ \\
Condylar plate $95^{\circ}+$ cerclage wire & $1(6.7)$ \\
Only cable wire & $1(6.7)$ \\
Individual implant & $2(13.3)$ \\
Dynamic hip screw & $7(46.7)$ \\
Non-operative & $8(53.3)$ \\
Time to osteosynthesis [days] mean \pm SD $(95 \%$-CI) & $2.0 \pm 1.6(0.6-3.3)$ \\
TOPS to fracture [months] mean \pm SD $(95 \%-C I)$ & $21.8 \pm 37.8(-9.8-53.3)$ \\
\hline
\end{tabular}

*DCS: dynamic condyle screw; **Less invasive stabilization system; ***Hannover Classification of postoperative periprosthetic Fractures (HCpopF) 
Student's $t$ test ${ }^{\mathrm{e}}$ was used for normal and Mann-Whitney $U$ test $^{\mathrm{b}}$ as well as Wilcoxon test ${ }^{\mathrm{c}}$ for non-normal variables. Fisher's exact ${ }^{\mathrm{a}}$ test and Pearson's Chi-squared test ${ }^{\mathrm{d}}$ were used for categorial variables. Significance was set to $p<0.05$.

\section{Results}

Follow-up data could be completely obtained from all patients $(n=15)$. Comorbidity was measured with Charlson Comorbidity Index (CCI) [13-15] and peri-/postoperative risk assed with American Society of Anesthesiologists (ASA) [16]. Detailed results are shown in Tables 1 and 2.
There was no significant difference for PMQ and K-level between the fracture and control group at follow-up times. In contrary, the fracture and control group showed a highly significant difference between PMQ and K-level before and after TOPS supply. Detailed results are shown in Figs. 2 and 3.

The subgroup analysis (BMI $<25 \mathrm{~kg} / \mathrm{m}^{2}$ vs. BMI $\geq 25 \mathrm{~kg} /$ $\left.\mathrm{m}^{2}\right)$ shows for the age at amputation $\left(p=0.002^{\mathrm{b}}\right)$ a significant difference between these two groups. Also, the comparison of the PMQ before and after TOPS showed significant differences. The comparison of the other parameters showed no significant difference. Detailed information is shown in Table 3 as well as Figs. 4 and 5.
Fig. 2 Graphical illustration of the comparison of the PMQ before and after TOPS for the fracture and control group

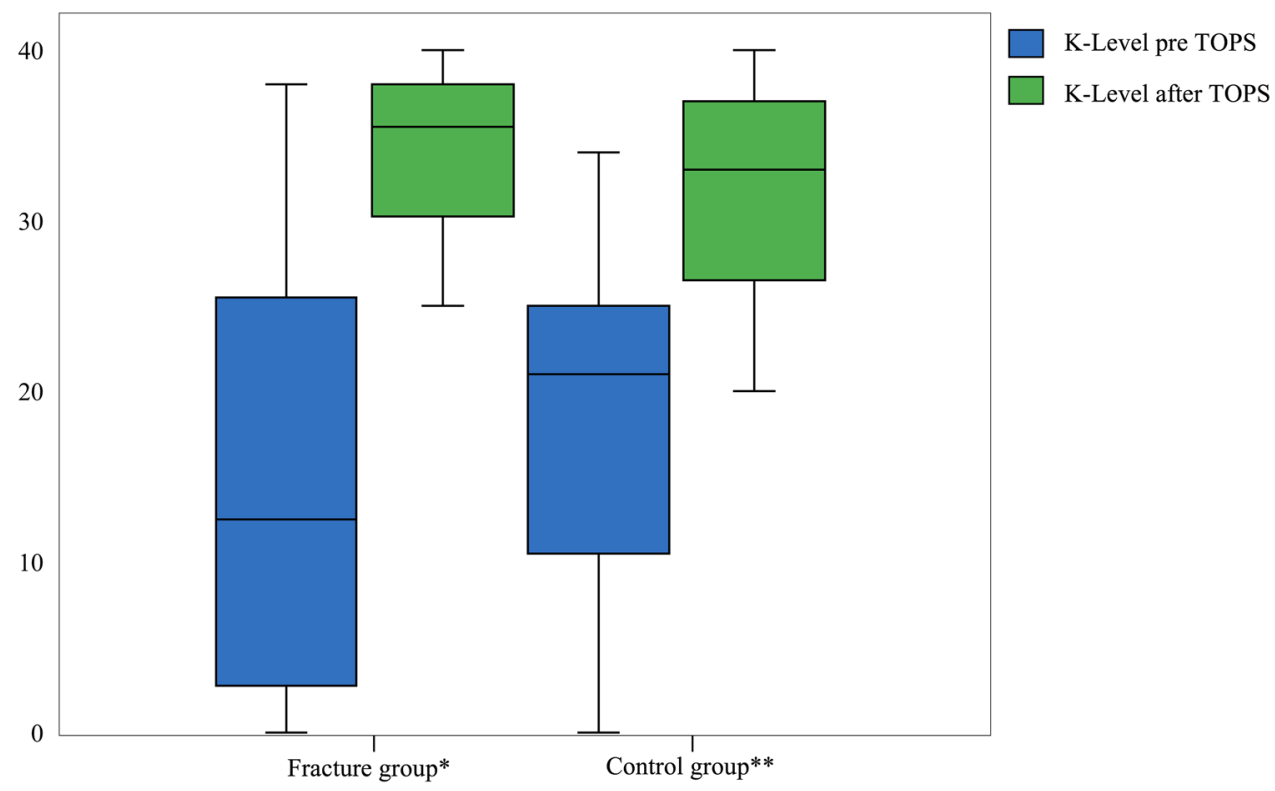

Fig. 3 Graphical illustration of the comparison of the K-level before and after TOPS for the fracture and control group

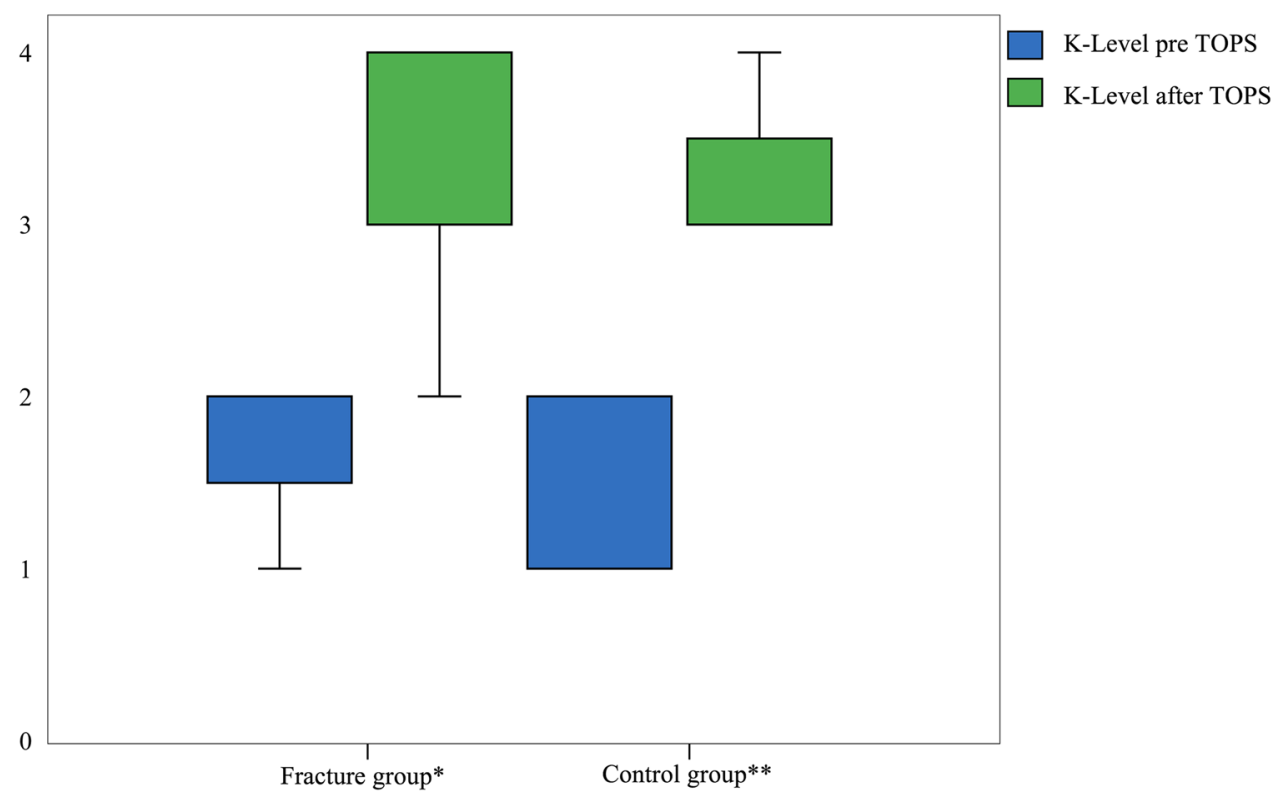


Table 3 Demographic data of the subgroups according to the BMI

\begin{tabular}{|c|c|c|c|}
\hline & $\mathrm{BMI}<25 \mathrm{~kg} / \mathrm{m}^{2}(n=12)$ & $\mathrm{BMI} \geq 25 \mathrm{~kg} / \mathrm{m}^{2}(n=22)$ & $p$ value \\
\hline BMI $\left[\mathrm{kg} / \mathrm{m}^{2}\right]$ mean $\pm \mathrm{SD}(95 \%-\mathrm{CI})$ & $22.2 \pm 2.1((20.8-23.5)$ & $29.1 \pm 3.0(27.7-30.4)$ & $0.002^{\mathrm{b}}$ \\
\hline $\operatorname{Sex}, n(\%)$ & & & $0.7^{\mathrm{a}}$ \\
\hline Male & $8(66.7)$ & $17(77.3)$ & \\
\hline Female & $4(33.3)$ & $5(22.7)$ & \\
\hline Side, $n(\%)$ & & & $0.049^{\mathrm{d}}$ \\
\hline Left & $6(50)$ & $15(68.2)$ & \\
\hline Right & $4(33.3)$ & $7(31.8)$ & \\
\hline Bilateral & $2(16.7)$ & 0 & \\
\hline Reason for amputation, $n(\%)$ & & & $0.1^{\mathrm{d}}$ \\
\hline Trauma & $10(83.3)$ & $13(59.1)$ & \\
\hline Tumor & $0(0)$ & $1(4.5)$ & \\
\hline Vascular disease & $1(8.3)$ & 0 & \\
\hline Iatrogenic complications & $1(8.3)$ & $8(36.4)$ & \\
\hline Fracture, $n(\%)$ & & & $0.7^{\mathrm{a}}$ \\
\hline Yes & $6(50)$ & $9(40.9)$ & \\
\hline No & $6(50)$ & $13(59.1)$ & \\
\hline Age [years] mean $\pm \mathrm{SD}(95 \%$-CI $)$ & $46.1 \pm 9.2(40.2-52.0)$ & $50.2 \pm 9.8(45.9-54.5)$ & $0.2^{\mathrm{e}}$ \\
\hline Age at amputation [years] mean \pm SD $(95 \%$-CI) & $25.8 \pm 11.2(18.7-33.0)$ & $36.9 \pm 12.4(31.4-42.3)$ & $<0.001^{\mathrm{b}}$ \\
\hline Months amputation to TOPS mean $\pm \mathrm{SD}(95 \%$-CI $)$ & $204.7 \pm 171.4(95.6-313.6)$ & $119.7 \pm 97.9(76.4-163.2)$ & $0.1^{\mathrm{e}}$ \\
\hline Use of prostheses [hours] mean $\pm \mathrm{SD}(95 \%-\mathrm{CI})$ & $11.9 \pm 4.9(8.8-15.0)$ & $13.2 \pm 3.5(11.7-14.8)$ & $0.6^{\mathrm{b}}$ \\
\hline ASA Score mean \pm SD $(95 \%-C I)$ & $1.9 \pm 0.3(1.7-2.1)$ & $2.1 \pm 0.4(1.9-2.2)^{* *}$ & $0.5^{\mathrm{d}}$ \\
\hline $\mathrm{CCI}[\%]$ mean $\pm \mathrm{SD}(95 \%-\mathrm{CI})$ & $97.2 \pm 1.0(96.5-97.8)$ & $92.8 \pm 10.7(88.0-97.5)^{* *}$ & $0.1^{\mathrm{b}}$ \\
\hline
\end{tabular}

Fig. 4 Graphical illustration of the comparison of the PMQ before and after TOPS for the subgroup analysis (BMI)

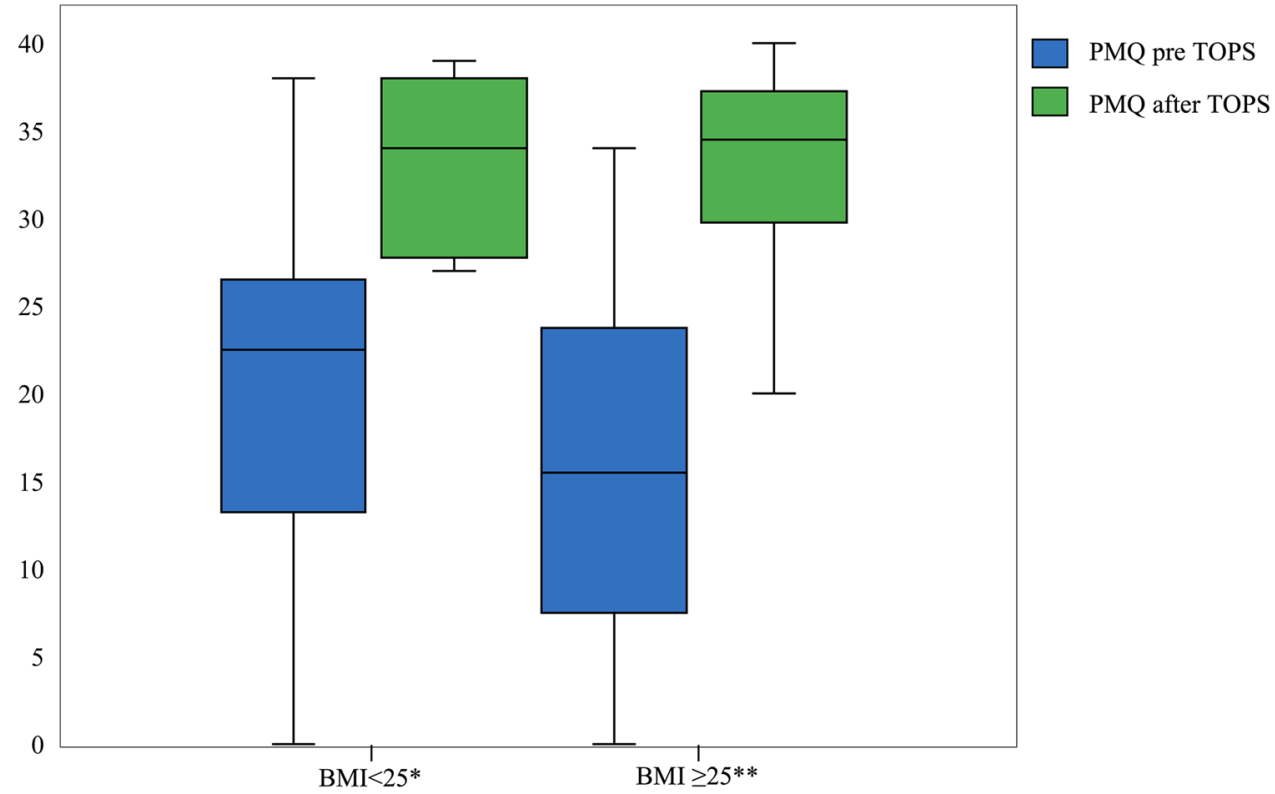

\section{Novel Classification System-Hannover Classification of intra- and postoperative periprosthetic Fractures (HCiopF, HCpopF) and treatment algorithm}

This rehabilitation system (TOPS) with its intramedullary implant which passes through the skin by two times surgery is new and still used only in a few centers worldwide. Therefore, treatment recommendations for such as cases are spares. Of particular note and in contrast to other classifications [22, 23], we recommend to not remove or exchange the implant (Endo-Fixstem) even if it is assembly. We assume that no relevant implant loosening occurs in the 
Fig. 5 Graphical illustration of the comparison of the K-level before and after TOPS for the subgroup analysis (BMI)

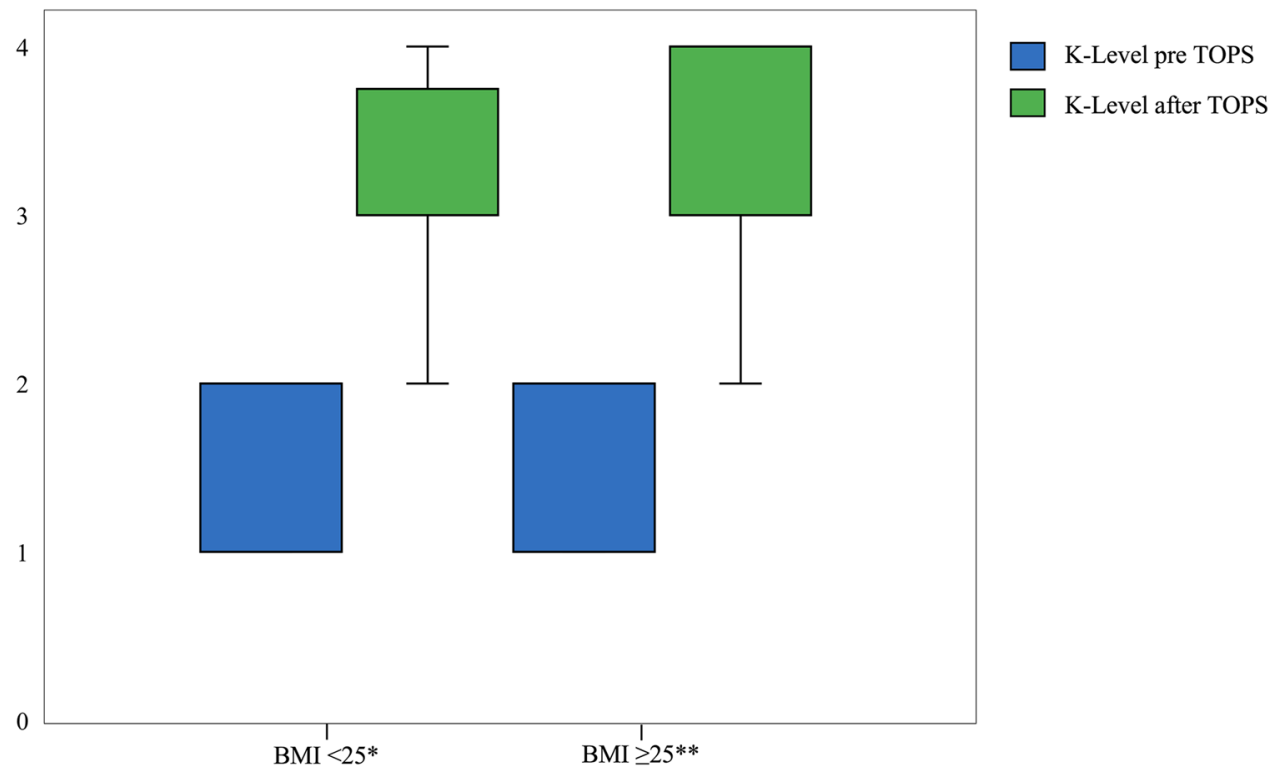

context of postoperative periprosthetic fractures due to the special surface structure (so-called tripods) of the endo-fixed stem and the circumferential osseointegration. If loosening does occur, the recommendation would still be just to perform implant-retaining osteosynthesis and whenever possible, not to remove the implant.

The novel classification system consists of three categories $\mathrm{A}-\mathrm{C}$ (Fig. 8). Category A represents the most simple and normally stable fracture morphology, such as a longitudinal split of the cortical bone and affecting the distal femur diaphysis. Oftentimes, conservative treatment is recommended for such cases of type $\mathrm{A}$. Type $\mathrm{C}$ represents the most difficult form of periprosthetic fractures, mostly unstable and affecting the metaphysis of the femur as well as the trochanteric region and requiring implant-retaining osteosynthesis. Type B contains fracture types in between types A and C. Detailed information about the classification and its treatments is shown in Tables 4 and 5.

\section{Discussion}

The most important finding of this study was that periprosthetic fractures following TOPS did not negatively affect outcomes.

For both the fracture and control group, a significant increase of the PMQ and K-level was observed before and after TOPS treatment. Subgroup analysis regarding BMI showed a significantly higher increase of the PMQ before and after TOPS for the group BMI $\geq 25$ than for the group

Table 4 Hannover Classification of intraoperative periprosthetic Fractures (HCiopF) as part of TOPS treatment and the treatment algorithm to the Hannover Classification of intraoperative periprosthetic Fractures (HCiopF)

\begin{tabular}{|c|c|c|c|}
\hline Type & Description & Subtypes & Treatment \\
\hline A & Fractures of the distal femoral bone & $\begin{array}{l}\text { 1: Simple cortical perforation* } \\
\text { 2: Undisplaced linear crack } \\
\text { 3: n/a }\end{array}$ & Local bone grafting, Protected weight bearing \\
\hline B & $\begin{array}{l}\text { Fractures affecting the proximal dia- } \\
\text { physis }\end{array}$ & $\begin{array}{l}\text { 1: Simple cortical perforation } \\
\text { 2: Undisplaced linear crack } \\
\text { 3: Displaced or unstable fracture }\end{array}$ & $\begin{array}{l}\text { 1. Local bone grafting, Protected weight bearing } \\
\text { 2. Local bone grafting, Protected weight bearing, cerclage } \\
\text { wire } \\
\text { 3. Internal fixation with cerclage wire, plate osteosynthe- } \\
\text { sis*** }\end{array}$ \\
\hline $\mathrm{C}$ & $\begin{array}{l}\text { Fractures affecting proximal } \\
\text { metaphysis and trochanteric region }\end{array}$ & $\begin{array}{l}\text { 1: Simple cortical perforation } \\
\text { 2: Undisplaced linear crack } \\
\text { 3: Displaced or unstable fracture }\end{array}$ & $\begin{array}{l}\text { 1. Local bone grafting, Protected weight bearing } \\
\text { 2. Local bone grafting, Protected weight bearing, cerclage } \\
\text { wire } \\
\text { 3. Internal fixation with cerclage wire, plate osteosynthe- } \\
\text { sis*** }\end{array}$ \\
\hline
\end{tabular}

*e.g., by intraoperative drilling; ***DHS, DCS plate, LISS plate, Condylplate, or individual implant 
Table 5 Hannover Classification of postoperative periprosthetic Fractures (HCpopF)as part of TOPS treatment as well as the treatment algorithm to the Hannover Classification of postoperative periprosthetic Fractures (HCpopF)

\begin{tabular}{|c|c|c|c|}
\hline Type & Description & Subtypes & Treatment \\
\hline A & $\begin{array}{l}\text { Fractures affecting the distal area of the } \\
\text { femoral bone }\end{array}$ & $\begin{array}{l}\text { 1: Undisplaced linear crack } \\
\text { 2: Displaced or unstable fracture }\end{array}$ & $\begin{array}{l}\text { 1. Local bone grafting, Protected weight } \\
\text { bearing } \\
\text { 2. Protected weight bearing, cerclage wire or } \\
\text { open reduction and internal fixation with } \\
\text { locking plate*** }\end{array}$ \\
\hline B & Fractures affecting the proximal diaphysis & $\begin{array}{l}\text { 1: Femoral stem well fixed } \\
\text { 2: Femoral stem loose } \\
\text { 3: Femoral stem loose with severe loss of } \\
\text { bone stock }\end{array}$ & $\begin{array}{l}\text { 1. Local bone grafting Protected weight } \\
\text { bearing } \\
\text { 2. Open reduction and internal fixation with } \\
\text { locking plate } \\
\text { 3. Open reduction and internal fixation with } \\
\text { locking plate*** }\end{array}$ \\
\hline $\mathrm{C}$ & $\begin{array}{l}\text { Fractures affecting proximal metaphysis } \\
\text { and trochanteric region }\end{array}$ & $\begin{array}{l}\text { 1. Trochanter minor (*undisplaced, } * * \text { dis- } \\
\text { placed) } \\
\text { 2. Trochanter major (displaced }>\text { or }<\text { two } \\
\text { centimeters) } \\
\text { 3. Inter-/subtrochanteric }\end{array}$ & $\begin{array}{l}\text { 1. * Local bone grafting Protected weight } \\
\text { bearing } \\
\text { 1. ** Protected weight bearing, internal } \\
\text { fixation } \\
\text { 2. }<2 \mathrm{~cm} \text { displaced: nonoperative } \\
\text { 2. }>2 \mathrm{~cm} \text { displaced: open reduction and } \\
\text { internal fixation } \\
\text { 3. Open reduction and internal fixation with } \\
\text { locking plate*** or proximal femoral } \\
\text { arthroplasty }\end{array}$ \\
\hline
\end{tabular}

***DHS, DCS-Plate, LISS-Plate, Condylplate or individual Implant

$\mathrm{BMI}<25$, regardless of a periprosthetic fracture. Subgroup analysis of the K-level also changed significantly for both groups before and after TOPS treatment. There was no significant improvement in the rehabilitation results for the K-level in favor of the overweight patients compared to the normal weight patients.

According to the findings of Hoellwarth et al. [12], our results confirm that periprosthetic fractures after TOPS treatment do not necessarily have a negative impact onto rehabilitation success. To the present time, all fracture fixations have been rehabilitated satisfactorily.

Surgical treatment of periprosthetic fractures after TOPS treatment was performed individually, according to their fracture morphology (Figs. 6, 7). The Endo-Fixstem never had to be exchanged or removed. In order to ensure a successful TOPS treatment, it is necessary to achieve a high primary stability in the first surgical step with a long press-fit anchorage [24]. For this purpose, the entire remaining diaphysis of the residual bone is mostly used for implant anchoring, resulting in placement of the tip of the Endo-Fixstem at the level of the lesser trochanter. In the context of a fall with a consecutive periprosthetic fracture, fractures are frequently encountered in the intertrochanteric and femoral neck area.

Based on the Vancouver Classification [22, 23] for intra- and postoperative periprosthetic fractures of total hip
Fig. 6 a-d Intraoperative periprosthetic fractures after implantation of the EndoFixstem; $\mathbf{c}$ the split fracture is covered by the implant; Only d needs an intraoperative fixation by cerclage cable
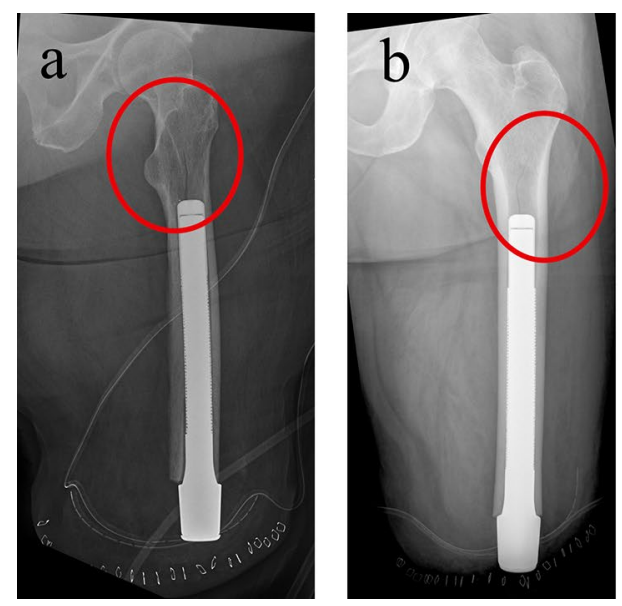

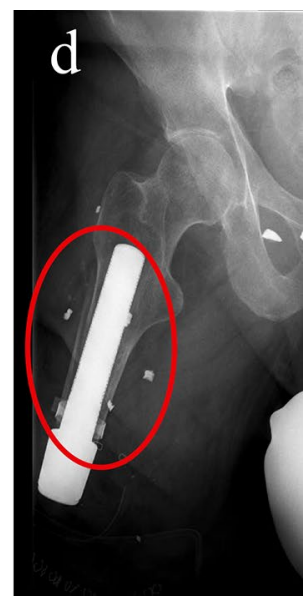



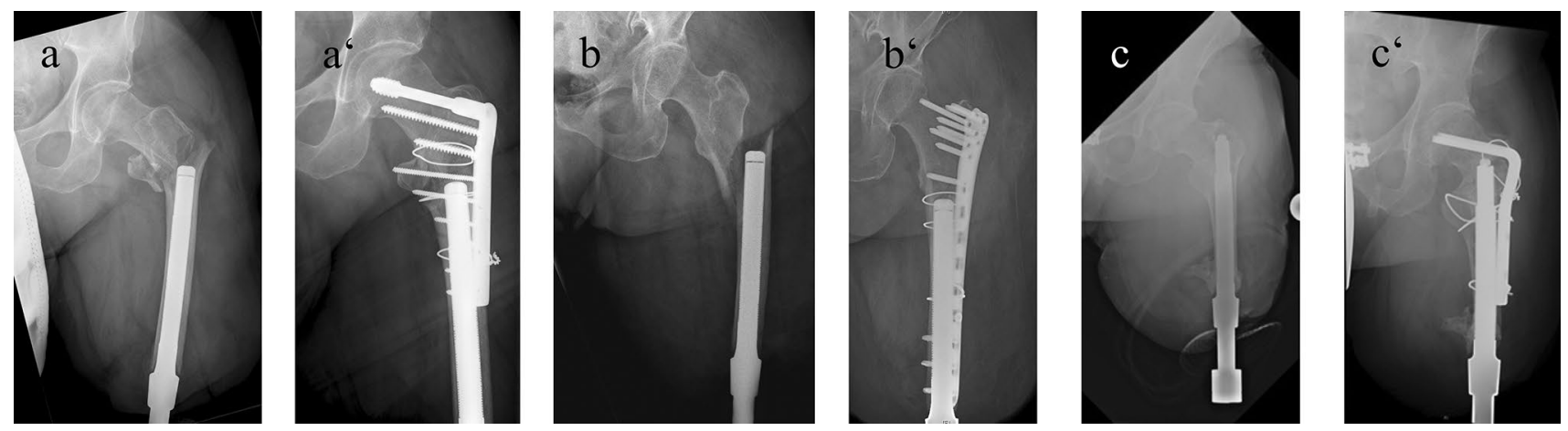

Fig. 7 a-c X-rays with postoperative periprosthetic fractures before and after open reduction and internal fixation with plates and cerclage cable

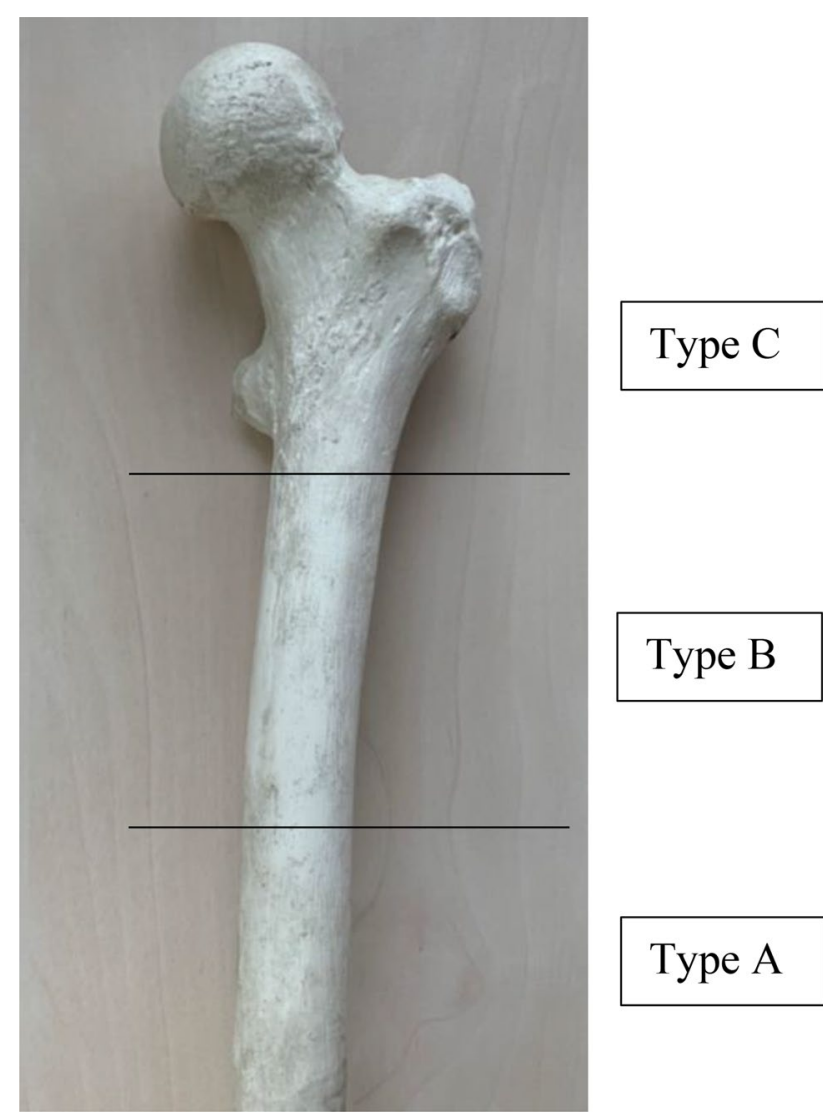

Fig. 8 Description of the level for intra- and postoperative periprosthetic fracture of the residual femur, fracture localization for classification

arthroplasty (THA), a novel Hannover Classification System and treatment recommendation (Fig. 8, Tables 4,5) of periprosthetic fractures after TOPS treatment was derived.

In contrast to the Vancouver Classification, it can be assumed that for postoperative periprosthetic fractures the Endo-Fixstem will not be loosen in most cases. Therefore, a change to a longer Endo-Fixstem with a hole containing a Femoral Lag Screw would not be possible or only with great effort. This is due to the fact that a very tight connection is formed between the surface structure (tripods) of the Endo-Fixstem and the bone [24-26]. This aspect could result in intraoperative fractures (Fig. 6). In postoperative periprosthetic fractures, it increases the degree of difficulty of implant-retaining osteosynthesis treatment, but could be a positive factor for rehabilitation after a periprosthetic fracture, since "only" the fracture would have to heal if the implant was firmly anchored. Tables 4 and 5 depict the classification and treatment algorithms.

Furthermore, it appears that overweight patients benefit even more from TOPS treatment than normal weight patients. Nevertheless, the BMI is regarded in the literature as a risk factor for complications such as periprosthetic fractures after arthroplasty surgeries [27]. In contrast to our results, both Hoffmann et al. and Canton et al. report a mean BMI of $32.4 \mathrm{~kg} / \mathrm{m}^{2}$ [28], and BMI $>30 \mathrm{~kg} / \mathrm{m}^{2}$ [29], respectively, considering this to be a predictor for a periprosthetic fracture.

Besides obesity, medical comorbidities such as cardiac and neurologic pathologies can contribute to ambulation instability with consecutively higher risk of fall and need to be considered as additional risk factors [29]. Other authors report that increased age and female gender may be a predictor of increased risk of periprosthetic fracture [29-35]. Again, this could not be confirmed in our cohort, which mainly consisted of younger (mean age 48.7 years) and predominantly male $(73.5 \%)$ patients. Derived from this, the incidence of periprosthetic fractures after TOPS could be attributed to an increased level of activity and an increased risk disposition [36].

Our study was conducted with a small cohort, but our results showed a significant improvement in mobility after TOPS treatment regardless of periprosthetic fracture. In consideration of the results of the subgroup analysis, future studies will be necessary to clarify whether the BMI should be considered a predictor for the rehabilitation success when using TOPS to major limb loss of the lower extremity. These 
aspects emphasize the importance of TOPS as a valid rehabilitation alternative for major limb loss.

The satisfactory results from the fracture group provide evidence for our chosen osteosynthesis procedures, so the derived classification and treatment algorithms could be included in the planning of the treatment of periprosthetic fractures according to TOPS in the future.

\section{Limitations}

A limiting factor is the low number of this cohort. This can be explained by still a rare use of TOPS as a rehabilitation alternative for transfemoral amputees both in Germany and worldwide. Since 2010, in Germany 140 patients have been treated with TOPS. In relation to this number of TOPS patients, the number of cases in the fracture group represents approximately $10 \%$ of all patients treated in Germany. However, it should be noted that five cases were intraoperative fractures that did not require further surgical intervention and could be treated sufficiently by a conservative procedure. In addition, widely spread time periods both between amputation and TOPS treatment, and between TOPS treatment and periprosthetic fractures were observed. It is unclear what bone quality at the time of implantation of the Endo-Fixstem TOPS user had, as an osteopenia bone structure according to time between amputation and TOPS treatment, can increase the risk of intra- and postoperative periprosthetic fractures. The limiting factors occurred involuntarily and randomly, so that these aspects could not direct influence the study design as a bias.

\section{Conclusion}

Periprosthetic fractures do not necessarily worsen outcomes of TOPS treatment. Proper classification, standardized appropriate treatment strategies according to fracture morphology are paramount for reliably good outcomes. We recommend to not remove or exchange the implant (EndoFixstem) even if it is assembly. Higher BMI did not have an impact onto rehabilitation success after TOPS to major limb loss of the lower extremity.

\begin{abstract}
Author contributions All authors contributed to the study conception and design. MÖ contributed to conceptualization; MÖ, MP, AR, and MW provided methodology; MÖ and NW performed formal analysis and investigation; MÖ, MP, and H-HA were involved in writingoriginal draft preparation; MÖ, TG, MW, and AR performed writing-review and editing; MÖ, H-HA, and TG provided resources; CK, MW, and MP performed supervision.
\end{abstract}

Funding Open Access funding enabled and organized by Projekt DEAL.

\section{Compliance with ethical standards}

Conflict of interest The authors declare that they have no competing interests.

Institutional review board/Ethics approval and consent to participate All procedures performed in studies involving human participants were in accordance with the ethical standards of the institutional and/ or national research committee and with the 1964 Helsinki Declaration and its later amendments or comparable ethical standards. Due to the retrospective data collection, ethical approval was given as a waiver (No. 8936_BO_K_2020) and consent was granted by the Ethics Committee of Hannover Medical School.

Consent to participate Informed consent was obtained from all individual participants included in the study.

Open Access This article is licensed under a Creative Commons Attribution 4.0 International License, which permits use, sharing, adaptation, distribution and reproduction in any medium or format, as long as you give appropriate credit to the original author(s) and the source, provide a link to the Creative Commons licence, and indicate if changes were made. The images or other third party material in this article are included in the article's Creative Commons licence, unless indicated otherwise in a credit line to the material. If material is not included in the article's Creative Commons licence and your intended use is not permitted by statutory regulation or exceeds the permitted use, you will need to obtain permission directly from the copyright holder. To view a copy of this licence, visit http://creativecommons.org/licenses/by/4.0/.

\section{References}

1. Aschoff HH, Juhnke DL (2012) Evaluation of 10 years experience with endo-exo femur prostheses-background, data and results. Z Orthop Unfall 150(6):607-614. https://doi. org/10.1055/s-0032-1327932

2. Juhnke DL, Beck JP, Jeyapalina S, Aschoff HH (2015) Fifteen years of experience with integral-leg-prosthesis: cohort study of artificial limb attachment system. J Rehabil Res Dev 52(4):407420. https://doi.org/10.1682/JRRD.2014.11.0280

3. Aschoff HH (2017) Transcutaneous osseointegration after limb amputation: a review over 27 years. Unfallchirurg 120(4):278 284. https://doi.org/10.1007/s00113-017-0329-y

4. Aschoff HH, Clausen A, Hoffmeister T (2009) The endo-exo femur prosthesis-a new concept of bone-guided, prosthetic rehabilitation following above-knee amputation. Z Orthop Unfall 147(5):610-615. https://doi.org/10.1055/s-0029-1185893

5. Aschoff HH, Clausen A, Tsoumpris K, Hoffmeister T (2011) Implantation of the endo-exo femur prosthesis to improve the mobility of amputees. Oper Orthop Traumatol 23(5):462-472. https://doi.org/10.1007/s00064-011-0054-6

6. Aschoff HH, Kennon RE, Keggi JM, Rubin LE (2010) Transcutaneous, distal femoral, intramedullary attachment for above-theknee prostheses: an endo-exo device. J Bone Jt Surg Am 92(Suppl 2):180-186. https://doi.org/10.2106/JBJS.J.00806

7. Juhnke DL, Aschoff HH (2015) Endo-exo prostheses following limb-amputation. Orthopade 44(6):419-425. https://doi. org/10.1007/s00132-015-3117-9

8. Branemark RP, Hagberg K, Kulbacka-Ortiz K, Berlin O, Rydevik B (2018) Osseointegrated percutaneous prosthetic system for the treatment of patients with transfemoral amputation: a prospective 
five-year follow-up of patient-reported outcomes and complications. J Am Acad Orthop Surg. https://doi.org/10.5435/JAAOS -D-17-00621

9. Leijendekkers RA, van Hinte G, Frolke JP, van de Meent H, Atsma F, Nijhuis-van der Sanden MW, Hoogeboom TJ (2018) Functional performance and safety of bone-anchored prostheses in persons with a transfemoral or transtibial amputation: a prospective one-year follow-up cohort study. Clin Rehabil. https://doi. org/10.1177/0269215518815215

10. Lindahl H, Garellick G, Regner H, Herberts P, Malchau H (2006) Three hundred and twenty-one periprosthetic femoral fractures. J Bone Jt Surg Am 88(6):1215-1222. https://doi.org/10.2106/ JBJS.E.00457

11. Van de Meent H, Hopman MT, Frolke JP (2013) Walking ability and quality of life in subjects with transfemoral amputation: a comparison of osseointegration with socket prostheses. Arch Phys Med Rehabil 94(11):2174-2178. https://doi.org/10.1016/j. apmr.2013.05.020

12. Hoellwarth JS, Tetsworth K, Kendrew J, Kang NV, van Waes O, Al-Maawi Q, Roberts C, Al Muderis M (2020) Periprosthetic osseointegration fractures are infrequent and management is familiar. Bone Jt J 102-B(2):162-169. https://doi. org/10.1302/0301-620X.102B2.BJJ-2019-0697.R2

13. Charlson ME, Pompei P, Ales KL, MacKenzie CR (1987) A new method of classifying prognostic comorbidity in longitudinal studies: development and validation. J Chronic Dis 40(5):373-383. https://doi.org/10.1016/0021-9681(87)90171-8

14. Quan H, Li B, Couris CM, Fushimi K, Graham P, Hider P, Januel JM, Sundararajan V (2011) Updating and validating the Charlson comorbidity index and score for risk adjustment in hospital discharge abstracts using data from 6 countries. Am J Epidemiol 173(6):676-682. https://doi.org/10.1093/aje/kwq433

15. Radovanovic D, Seifert B, Urban P, Eberli FR, Rickli H, Bertel O, Puhan MA, Erne P, Investigators AP (2014) Validity of Charlson Comorbidity Index in patients hospitalised with acute coronary syndrome. Insights from the nationwide AMIS Plus registry 2002-2012. Heart 100(4):288-294. https://doi.org/10.1136/heart jnl-2013-304588

16. Saklad M (1941) Grading of patients for surgical procedures. Anesthesiol J Am Soc Anesthesiol 2(3):281-284

17. Franchignoni F, Monticone M, Giordano A, Rocca B (2015) Rasch validation of the Prosthetic Mobility Questionnaire: a new outcome measure for assessing mobility in people with lower limb amputation. J Rehabil Med 47(5):460-465. https://doi. org/10.2340/16501977-1954

18. Burger H, Giordano A, Bavec A, Franchignoni F (2019) The Prosthetic Mobility Questionnaire, a tool for assessing mobility in people with lower-limb amputation: validation of PMQ 20 in Slovenia. Int J Rehabil Res 42(3):263-269. https://doi.org/10.1097/ MRR.0000000000000354

19. Gailey RS, Roach KE, Applegate EB, Cho B, Cunniffe B, Licht S, Maguire M, Nash MS (2002) The amputee mobility predictor: an instrument to assess determinants of the lower-limb amputee's ability to ambulate. Arch Phys Med Rehabil 83(5):613-627. https ://doi.org/10.1053/ampr.2002.32309

20. Engstrom B, Van de Van C (1999) Therapy for amputees. Churchill Livingstone Inc, Philadelphia, 332 pp

21. Dudek NL, Khan OD, Lemaire ED, Marks MB, Saville L (2008) Ambulation monitoring of transtibial amputation subjects with patient activity monitor versus pedometer. J Rehabil Res Dev 45(4):577-585. https://doi.org/10.1682/jrrd.2007.05.0069

22. Greidanus NV, Mitchell PA, Masri BA, Garbuz DS, Duncan CP (2003) Principles of management and results of treating the fractured femur during and after total hip arthroplasty. Instr Course Lect 52:309-322
23. Duncan CP, Masri BA (1995) Fractures of the femur after hip replacement. Instr Course Lect 44:293-304

24. Orgel M, Liodakis E, Jaratjitwilai P, Harb A, Wirries N, Omar M, Krettek C, Aschoff HH (2020) Three-year follow-up of changes of cortical bone thickness after implantation of Endo-Exo-Prosthesis (EEP) for transfemoral amputees. J Orthop Surg Res 15(1):164. https://doi.org/10.1186/s13018-020-01675-w

25. Gradinger R, Gollwitzer H (2006) Ossäre Integration, vol 1. Springer, Berlin. https://doi.org/10.1007/978-3-540-35687-5

26. Mittelmeier W, Grunwald I, Schafer R, Grundei H, Gradinger R (1997) Cementless fixation of the endoprosthesis using trabecular, 3-dimensional interconnected surface structures. Orthopade 26(2):117-124

27. Lubbeke A, Stern R, Garavaglia G, Zurcher L, Hoffmeyer P (2007) Differences in outcomes of obese women and men undergoing primary total hip arthroplasty. Arthritis Rheum 57(2):327-334. https://doi.org/10.1002/art.22542

28. Hoffmann MF, Jones CB, Sietsema DL, Koenig SJ, Tornetta P 3rd (2012) Outcome of periprosthetic distal femoral fractures following knee arthroplasty. Injury 43(7):1084-1089. https://doi. org/10.1016/j.injury.2012.01.025

29. Canton G, Ratti C, Fattori R, Hoxhaj B, Murena L (2017) Periprosthetic knee fractures. A review of epidemiology, risk factors, diagnosis, management and outcome. Acta Biomed 88(2S):118-128. https://doi.org/10.23750/abm.v88i2-S.6522

30. Gondalia V, Choi DH, Lee SC, Nam CH, Hwang BH, Ahn HS, Ong AC, Park HY, Jung KA (2014) Periprosthetic supracondylar femoral fractures following total knee arthroplasty: clinical comparison and related complications of the femur plate system and retrograde-inserted supracondylar nail. J Orthop Traumatol 15(3):201-207. https://doi.org/10.1007/s10195-014-0287-x

31. Meek RM, Norwood T, Smith R, Brenkel IJ, Howie CR (2011) The risk of peri-prosthetic fracture after primary and revision total hip and knee replacement. J Bone Jt Surg Br 93(1):96-101. https ://doi.org/10.1302/0301-620X.93B1.25087

32. Chalidis BE, Tsiridis E, Tragas AA, Stavrou Z, Giannoudis PV (2007) Management of periprosthetic patellar fractures. A systematic review of literature. Injury 38(6):714-724

33. Singh JA, Jensen MR, Lewallen DG (2012) Patient factors predict periprosthetic fractures after revision total hip arthroplasty. J Arthroplasty 27(8):1507-1512. https://doi.org/10.1016/j. arth.2011.12.010

34. Memtsoudis SG, Ma Y, Gonzalez Della Valle A, Besculides MC, Gaber LK, Koulouvaris P, Liu SS (2010) Demographics, outcomes, and risk factors for adverse events associated with primary and revision total hip arthroplasties in the United States. Am J Orthop (Belle Mead NJ) 39(8):E72-77

35. Mahomed NN, Barrett JA, Katz JN, Phillips CB, Losina E, Lew RA, Guadagnoli E, Harris WH, Poss R, Baron JA (2003) Rates and outcomes of primary and revision total hip replacement in the United States medicare population. J Bone Jt Surg Am 85(1):2732. https://doi.org/10.2106/00004623-200301000-00005

36. Fuchs M, Perka C, von Roth P (2016) Periprosthetic fractures following total hip and knee arthroplasty: risk factors, epidemiological aspects, diagnostics and classification systems. Unfallchirurg 119(3):185-193. https://doi.org/10.1007/s00113-016-0144-x

Publisher's Note Springer Nature remains neutral with regard to jurisdictional claims in published maps and institutional affiliations. 